Pacific Journal of Mathematics

ABSOLUTE NÖRLUND SUMMABILITY FACTORS FOR

G. D. DIKSHIT 


\title{
ABSOLUTE NÖRLUND SUMMABILITY FACTORS FOR FOURIER SERIES
}

\author{
G. D. DiKshit
}

In this paper a general theorem on the absolute Nörlund summability factors of a Lebesgue-Fourier series at a given point has been established. The theorem exhibits the potency of a Nörlund method as a tool to study absolute summability and the absolute convergence of Fourier series. Several existing results in the field are deduced as special cases. This also shows some sort of continuity amongst these theorems which otherwise seem apparently to be disconnected.

1. Let $\left\{p_{n}\right\}$ be a sequence of constants such that

$$
P_{n}=p_{0}+p_{1}+\cdots+p_{n} \neq 0, \text { for } n=0,1,2, \cdots \text {. }
$$

Given a series $\sum u_{n}$ we define $\left\{t_{n}\right\}$ of its Nörlund means by

$$
t_{n}=\frac{1}{P_{n}} \sum_{0}^{n} P_{k} u_{n-k} \text {. }
$$

The series $\Sigma u_{n}$ is said to be summable $\left|N, p_{n}\right|$ and we write $\Sigma u_{n} \epsilon$ $\left|N, p_{n}\right|$, if the sequence $\left\{t_{n}\right\} \in b v$, that is $\Sigma\left|\Delta t_{n}\right| \equiv \Sigma\left|t_{n}-t_{n+1}\right|$ is convergent.

In the special case when $p_{n}=\Gamma(n+k) / \Gamma(k) \Gamma(n+1), k>0$, the summability $\left|N, p_{n}\right|$ reduces to the familiar Cesàro summability $|C, k|$ and when $p_{n}=1 /(n+1)$, it is the same as the absolute harmonic summability.

2. Let $f$ be a periodic function with period $2 \pi$ and let $f \in$ $L(-\pi, \pi)$. Let the Fourier series of $f$ at a point $x$ be given by

$$
f(x) \sim \frac{1}{2} a_{0}+\sum_{1}^{\infty}\left(a_{n} \cos n x+b_{n} \sin n x\right) \equiv \sum_{0}^{\infty} A_{n}(x) .
$$

Throughout the paper we use the following notations:

$$
\begin{aligned}
\dot{\phi}(t) & =\frac{1}{2}\{f(x+t)+f(x-t)\}, \\
\Phi_{0}(t) & =\phi(t), \\
\Phi_{\alpha}(t) & =\frac{1}{\Gamma(\alpha)} \int_{0}^{t}(t-u)^{\alpha-1} \phi(u) d u, \alpha>0, \\
\phi_{\alpha}(t) & =\Gamma(\alpha+1) t^{-\alpha} \Phi_{\alpha}(t), \alpha \geqq 0, \\
G(n, t) & =P_{n}^{-1} \sum_{0}^{n-1} p_{k} \varepsilon_{n-k} e^{i(n-k) t},
\end{aligned}
$$




$$
\begin{aligned}
g(n, t)= & \operatorname{Im}(G(n, t)), \\
H(n, t)= & \frac{P_{\tau}}{P_{n}}\left(\left|\varepsilon_{n-m}\right|+\frac{1}{n} \sum_{n-m}^{n+1}\left|\varepsilon_{k}\right|\right)+\frac{p_{m}}{t P_{n}}, \\
& \text { where } \tau=[1 / t] \text { and } m=[(1 / 2) n], \\
J(n, t)= & \frac{1}{\Gamma(1-\alpha)} \int_{t}^{\pi}(w-t)^{-\alpha} \frac{d}{d w} g(n, w) d w, 0 \leqq \alpha<1, \\
L(n, t)= & \frac{1}{\Gamma(\alpha+1)} \int_{t}^{\pi} u^{\alpha} \frac{d}{d u} J(n, u) d u, 0 \leqq \alpha<1, \\
V(n, t)= & \frac{1}{\Gamma(\alpha+1)} \int_{0}^{t} u^{\alpha} \frac{d}{d u} J(n, u) d u, 0 \leqq \alpha<1 .
\end{aligned}
$$

$K, K_{1}, K_{2}, \cdots$, denote absolute constants not necessarily the same at different occurrences.

$B$ denotes the class of bounded sequences and

$\mathscr{C}$ denotes a class of positive and nonincreasing sequences:

$$
\mathscr{L}=\left\{s_{n}: s_{n}>0, \frac{s_{n+1}}{s_{n}} \leqq \frac{s_{n+2}}{s_{n+1}} \leqq 1\right\} .
$$

3. Since the publication of the classical theorems of Bosanquet ([3], [4]) on absolute Cesàro summability of a Fourier series in 1936, various results have been worked out on absolute Cesàro summability, absolute harmonic summability and absolute Nörlund summability of Fourier series and series related with it. The purpose of this paper is to furnish a general theorem on the absolute Nörlund summability of a Fourier series from which we deduce several known and unknown results.

We establish the following theorem:

THEOREM. Let $\alpha$ satisfy $0 \leqq \alpha<1$ and let $\left\{p_{n}\right\} \in \mathscr{M}$ and $\left\{\varepsilon_{n}\right\} \in$ bv be such that

(i ) $\sum_{n}^{\infty}\left|\Delta \varepsilon_{k}\right|=O\left(\left|\varepsilon_{n}\right|\right)$ and

(ii) $\left\{\frac{P_{n}}{n^{\alpha}} \sum_{n}^{\infty} \frac{\left|\varepsilon_{k}\right|}{k^{1-\alpha} P_{k}}\right\} \in B$.

If $\phi_{\alpha}(t) \in B V(0, \pi)$, then $\sum A_{n}(x) \varepsilon_{n} \in\left|N, p_{n}\right|$.

4. We use the results in the following lemmas towards the proof of our theorem.

LEMmA 1 (McFadden [13]). If $\left\{p_{n}\right\}$ is a nonnegative nonincreasing sequence then for $0<t \leqq \pi$ and for any $n, a$ and $b$ 


$$
\left|\sum_{a}^{b} p_{k} e^{i(n-k) t}\right| \leqq K P_{[1 / t]}
$$

LEMMA 2. Let $\left\{p_{n}\right\}$ be a nonnegative nonincreasing sequence and $\left\{\varepsilon_{n}\right\} \in b v$ be such that $\sum_{n}^{2 n}\left|\Delta \varepsilon_{k}\right|=O\left(\left|\varepsilon_{n}\right|\right)$. Then for $1 / n<t \leqq$ $\pi, \tau=[1 / t]$ and $m=[(1 / 2) n]$,

$$
\begin{gathered}
G(n, t)=O\left(\frac{P_{\tau}\left|\varepsilon_{n-m}\right|}{P_{n}}\right)+O\left(\frac{p_{m}}{t P_{n}}\right) ; \\
\frac{d}{d t} G(n, t)=O(n H(n, t)) ;
\end{gathered}
$$

and

$$
L(n, t)=O\left(n^{\alpha} t^{\alpha} H(n, t)\right)
$$

Proof. (i) Let

$$
\begin{aligned}
P_{n} G(n, t) & =\left(\sum_{0}^{m}+\sum_{m+1}^{n-1}\right) p_{k} \varepsilon_{n-k} e^{i(n-k) t} \\
& =S_{1}+S_{2} .
\end{aligned}
$$

Then by Lemma 1

$$
\begin{aligned}
S_{1} & =O\left(P_{\tau}\left\{\left|\varepsilon_{n-m}\right|+\sum_{0}^{m-1}\left|\Delta \varepsilon_{n-k}\right|\right\}\right) \\
& =O\left(P_{\tau}\left|\varepsilon_{n-m}\right|\right),
\end{aligned}
$$

and

$$
\begin{aligned}
S_{2} & =\sum_{1}^{n-m-1} p_{n-k} \varepsilon_{k} e^{i k t} \\
& =O\left(\frac{1}{t}\right)\left\{p_{m+1}+\sum_{1}^{n-m-2}\left|\Delta\left(\varepsilon_{k} p_{n-k}\right)\right|\right\} \\
& =O\left(\frac{1}{t}\right)\left\{p_{m+1}+\sum_{1}^{n-m-2}\left|\varepsilon_{k}\right|\left(p_{n-k-1}-p_{n-k}\right)+\sum_{1}^{n-m-2} p_{n-k-1}\left|\Delta \varepsilon_{k}\right|\right\} \\
& =O\left(\frac{p_{m}}{t}\right),
\end{aligned}
$$

by hypotheses.

(ii) Let

$$
\begin{aligned}
P_{n} \frac{d}{d t} G(n, t) & =\left(\sum_{0}^{m}+\sum_{m+1}^{n-1}\right) p_{k} \varepsilon_{n-k}(n-k) i e^{i(n-k) t} \\
& =S_{3}+S_{4} .
\end{aligned}
$$


Then, proceeding as above in (i)

$$
\begin{aligned}
S_{3} & =O\left(P_{\tau}\right)\left\{(n-m)\left|\varepsilon_{n-m}\right|+\sum_{0}^{m-1}\left|\Delta\left((n-k) \varepsilon_{n-k}\right)\right|\right\} \\
& =O\left(P_{\tau}\right)\left\{n\left|\varepsilon_{n-m}\right|+\sum_{n-m}^{n-1} k\left|\Delta \varepsilon_{k}\right|+\sum_{n-m}^{n-1}\left|\varepsilon_{k+1}\right|\right\} \\
& =O\left(P_{\tau}\right)\left\{n\left|\varepsilon_{n-m}\right|+\sum_{n-m}^{n}\left|\varepsilon_{k}\right|\right\} ; \\
S_{4} & =\sum_{1}^{n-m-1} k \varepsilon_{k} p_{n-k} i e^{i k t} \\
& =O(1 / t)\left\{(n-m-1)\left|\varepsilon_{n-m-1}\right| p_{m+1}+\sum_{1}^{n-m-2}\left|\Delta\left(k \varepsilon_{k} p_{n-k}\right)\right|\right\} \\
& =O(1 / t)\left\{n p_{m}+\sum_{1}^{n-m-2} k\left|\Delta\left(\varepsilon_{k} p_{n-k}\right)\right|+\sum_{1}^{n-m-1} p_{n-k}\left|\varepsilon_{k}\right|\right\} \\
& =O(n / t)\left\{p_{m}+\sum_{1}^{n-m-2}\left|\Delta\left(\varepsilon_{k} p_{n-k}\right)\right|\right\} \\
& =O\left(n p_{m} / t\right) .
\end{aligned}
$$

(iii) We have

$$
\begin{aligned}
\Gamma(1-\alpha) J(n, t) & =\left(\int_{t}^{t+1 / n}+\int_{t+1 / n}^{\pi}\right)(u-t)^{-\alpha} \frac{d}{d u} g(n, u) d u \\
& =I_{1}+I_{2}, \text { say . } \\
I_{1} & =O(n H(n, t)) \int_{t}^{t+1 / n}(u-t)^{-\alpha} d u, \text { by (ii), } \\
& =O\left(n^{\alpha} H(n, t)\right),
\end{aligned}
$$

and

$$
\begin{aligned}
I_{2} & =O\left(n^{\alpha}\right)\left|[g(n, u)]_{t+1 / n}^{\pi^{\prime}}\right|, t+\frac{1}{n}<\pi^{\prime} \leqq \pi, \\
& =O\left(\frac{n^{\alpha}}{P_{n}}\right)\left\{P_{\tau}\left|\varepsilon_{n-m}\right|+\frac{p_{m}}{t}\right\}, \text { by } \quad \text { (i) } .
\end{aligned}
$$

Therefore

$$
\begin{aligned}
\Gamma(\alpha & +1)|L(n, t)|=\left|\left[u^{\alpha} J(n, u)\right]_{t}^{\pi}-\alpha \int_{t}^{\pi} u^{\alpha-1} J(n, u) d u\right| \\
& =\left|t^{\alpha} J(n, t)+\frac{\alpha}{\Gamma(1-\alpha)} \int_{t}^{\pi} u^{\alpha-1} \int_{u}^{\pi}(w-u)^{-\alpha} \frac{d}{d w} g(n, w) d w d u\right| \\
& =\left|t^{\alpha} J(n, t)+\frac{\alpha}{\Gamma(1-\alpha)} \int_{t}^{\pi} \frac{d}{d w} g(n, w) d w \int_{t}^{w}(w-u)^{-\alpha} u^{\alpha-1} d u\right| \\
& =\left|t^{\alpha} J(n, t)+\frac{\alpha}{\Gamma(1-\alpha)} \int_{t}^{\pi} \frac{d}{d w} g(n, w) d w \int_{t / w}^{1} u^{\alpha-1}(1-u)^{-\alpha} d u\right| \\
& \leqq K_{1} t^{\alpha}|J(n, t)|+K_{2}\left|g\left(n, t^{\prime}\right)\right|, t \leqq t^{\prime}<\pi .
\end{aligned}
$$


$\Rightarrow L(n, t)=O\left(n^{\alpha} t^{\alpha} H(n, t)\right)$.

Lemma 3 (Das [6]). Let $\left\{p_{n}\right\} \in \mathscr{C l}$. Then $\sum u_{n} \in\left|N, p_{n}\right|$, if and only if

$$
\sum_{1}^{\infty} \frac{1}{n P_{n}}\left|\sum_{1}^{n} p_{n-k} k u_{k}\right|<\infty
$$

5. Proof of the Theorem. Let

$$
T_{n} \equiv T_{n}(x)=\frac{1}{P_{n}} \sum_{1}^{n} p_{n-k} k A_{k}(x) \varepsilon_{k} .
$$

Then by Lemma 3 , it is sufficient to show that

$$
\sum \frac{\left|T_{n}\right|}{n}<\infty
$$

As

$$
\begin{aligned}
k A_{k}(x) & =\frac{2}{\pi} \int_{0}^{\pi} \phi(t) \frac{d}{d t} \sin k t d t, \\
\frac{\pi}{2} T_{n} & =\frac{1}{P_{n}} \sum_{1}^{n} p_{n-k} \varepsilon_{k} \int_{0}^{\pi} \phi(t) \frac{d}{d t} \sin k t d t \\
& =\int_{0}^{\pi} \phi(t) \frac{d}{d t} g(n, t) d t \\
& =\frac{1}{\Gamma(1-\alpha)} \int_{0}^{\pi} \frac{d}{d t} g(n, t) \int_{0}^{t}(t-u)^{-\alpha} d \Phi_{\alpha}(u) d t, 0<\alpha<1, \\
& =\frac{1}{\Gamma(1-\alpha)} \int_{0}^{\pi} d \Phi_{\alpha}(u) \int_{u}^{\pi}(t-u)^{-\alpha} \frac{d}{d t} g(n, t) d t \\
& =-\int_{0}^{\pi} \Phi_{\alpha}(u) \frac{d}{d u} J(n, u) d u, 0 \leqq \alpha<1, \\
& =-\left[\phi_{\alpha}(u) V(n, d)\right]_{0}^{\pi}+\int_{0}^{\pi} V(n, u) d \phi_{\alpha}(u) \\
& =-\phi_{\alpha}(\pi) V(n, \pi)+\int_{0}^{\pi} V(n, u) d \phi_{\alpha}(u) .
\end{aligned}
$$

If in particular we choose $\phi(t)=1$, then $\phi_{\alpha}(t)=1$ and $T_{n}=0$ for every $n$. Hence

$$
V(n, \pi)=0
$$

Thus

$$
\frac{\pi}{2} T_{n}=\int_{0}^{\pi} V(n, u) d \phi_{\alpha}(u)
$$


As $\phi_{\alpha}(t) \in B V(0, \pi)$, to complete the poof it is sufficient to show that uniformly in $t, 0<t \leqq \pi$

$$
\sum \frac{|V(n, t)|}{n} \leqq K
$$

Since $V(n, t)+L(n, t)=0$, we have

$$
\sum \frac{|V(n, t)|}{n} \leqq \sum_{1}^{\tau} \frac{|V(n, t)|}{n}+\sum_{\tau+1}^{\infty} \frac{|L(n, t)|}{n} .
$$

As

$$
|g(n, t)| \leqq \frac{1}{P_{n}} \sum_{0}^{n-1} p_{k}\left|\varepsilon_{n-k}\right| \leqq K
$$

and

$$
\left|\frac{d}{d t} g(n, t)\right| \leqq \frac{1}{P_{n}} \sum_{0}^{n-1} p_{k}(n-k)\left|\varepsilon_{n-k}\right| \leqq K n,
$$

we have

$$
\begin{aligned}
\Gamma(1-\alpha) J(n, t) & =\left(\int_{t}^{t+1 / n}+\int_{t+1 / n)}^{\pi}\right),(u-t)^{-a} \frac{d}{d u} g(n, u) d u \\
& =\text { etc. } \\
& =O\left(n^{a}\right) .
\end{aligned}
$$

Hence, for $0<\alpha<1$,

$$
\Gamma(1+\alpha)|V(n, t)|=\left|\left[u^{\alpha} J(n, u)\right]_{0}^{t}-\alpha \int_{0}^{t} u^{\alpha-1} J(n, u) d u\right| \leqq K n^{\alpha} t^{\alpha},
$$

and

$$
\sum_{1}^{\tau} \frac{|V(n, t)|}{n} \leqq K t^{\alpha} \sum_{1}^{\tau} n^{\alpha-1} \leqq K
$$

For $\alpha=0$, we note that

$$
|V(n, t)|=|g(n, t)| \leqq \frac{1}{P_{n}} \sum_{0}^{n-1} p_{k}\left|\varepsilon_{n-k}\right|(n-k) t \leqq n t,
$$

and thus again

$$
\sum_{1}^{\tau} \frac{|V(n, t)|}{n} \leqq K
$$

Therefore, after Lemma 2(iii), it is sufficient to show that

$$
t^{\alpha} \sum_{\tau+1}^{\infty} n^{\alpha-1}|H(n, t)| \leqq K,
$$


uniformly in $t, 0<t \leqq \pi$. However

$$
\begin{aligned}
t^{\alpha} \sum_{\tau+1}^{\infty} & n^{\alpha-1}|H(n, t)| \\
& =P_{\tau} t^{\alpha} \sum_{\tau+1}^{\infty} \frac{n^{\alpha-1}}{P_{n}}\left|\varepsilon_{n-m}\right|+P_{\tau} t^{\alpha} \sum_{\tau+1}^{\infty} \frac{n^{\alpha-2}}{P_{n}} \sum_{n-m}^{n+1}\left|\varepsilon_{k}\right|+t^{\alpha-1} \sum_{\tau+1}^{\infty} \frac{n^{\alpha-1} p_{m}}{P_{n}} \\
& \leqq K_{1}+P_{\tau} t_{\left[{ }_{[\tau+1) / 2]}^{\alpha}\right.}^{\infty}\left|\varepsilon_{k}\right| \sum_{n=k-1}^{2 k} \frac{n^{\alpha-2}}{P_{n}}+K_{2} t^{\alpha-1} \sum_{\tau+1}^{\infty} n^{\alpha-2} \\
& \leqq K_{1}+K_{2} P_{\tau} t^{\alpha} \sum_{[\tau+1) / 2]}^{\infty} \frac{\left|\varepsilon_{k}\right|}{k^{1-\alpha} P_{k}} \\
& \leqq K .
\end{aligned}
$$

This completes the proof of the theorem.

\section{Corollaries.}

6.1. Taking $p_{n}=\Gamma(n+\beta) / \Gamma(\beta) \Gamma(n+1), 1 \geqq \beta>0$, we get

COROLLARY 1. Let $\alpha$ satisfy $0 \leqq \alpha<1$, and let $\left\{\varepsilon_{n}\right\} \in b v$ be such that

(i ) $\sum_{n}^{\infty}\left|\Delta \varepsilon_{k}\right|=O\left(\left|\varepsilon_{n}\right|\right)$ and

(ii) $\left\{n^{\beta-\alpha} \sum_{n}^{\infty} \frac{\left|\varepsilon_{k}\right|}{k^{1+\beta-\alpha}}\right\} \in B$.

If $\phi_{\alpha}(t) \in B V(0, \pi)$, then $\sum A_{n}(x) \varepsilon_{n} \in|C, \beta|, \beta \geqq \alpha$.

The case $\left\{\varepsilon_{n}\right\} \equiv\{1\}$, and $\beta>\alpha$, furnishes corresponding results due to Bosanquet ([3], [4]). Taking $0<\alpha=\beta<1$ and specializing $\left\{\varepsilon_{n}\right\}$ to $\left\{(\log (n+1))^{-1-\varepsilon}\right\}, \varepsilon>0$, we get a result due to Cheng ([5]). Again in the case $\alpha=\beta$, taking $\left\{\varepsilon_{n}\right\}$ to be a convex sequence (see Zygmund [18], p. 93, for the definition and certain properties as needed) we obtain a result due to Prasad and Bhatt ([14]). The case $\beta=\alpha=0$ is covered in Corollary 3 below.

6.2. The case $p_{n}=1 /(n+1)$ furnishes the following result on absolute harmonic summability:

Corollary 2. Let $\alpha$ satisfy $0 \leqq \alpha<1$, and let $\left\{\varepsilon_{n}\right\} \in b v$ be such that

(i ) $\sum_{n}^{\infty}\left|\Delta \varepsilon_{k}\right|=O\left(\left|\varepsilon_{n}\right|\right)$ and

(ii) $\left\{\frac{\log n}{n^{\alpha}} \sum_{n}^{\infty} \frac{\left|\varepsilon_{k}\right|}{k^{1-\alpha} \log k}\right\} \in B$.

If $\phi_{\alpha}(t) \in B V(0, \pi)$, then $\sum A_{n}(x) \varepsilon_{n} \in|N, 1 / n+1|$. 
The case $\alpha=0$, includes a well known theorem due to Varshney ([17], Varshney has proved the result for $\left.\left\{\varepsilon_{n}\right\}=\{1 / \log (n+2)\}\right)$. Specialising $\left\{\varepsilon_{n}\right\}$ to be $\left\{\log (n+1) \lambda_{n} / n^{\alpha}\right\}$, where $\left\{\lambda_{n}\right\}$ is a convex sequence, we get the result due to Bhatt [1].

6.3. It is now known (see Dikshit [8]) that if $\left\{p_{n}\right\} \in \mathscr{C}$ and $\left\{P_{n}\right\} \in B$ then the method $\left|N, p_{n}\right|$ is ineffective, in the sense that it sums only absolutely convergent series. Thus the extra hypothesis that $\left\{P_{n}\right\} \in B$ in the theorem yields the following result on absolute convergence factors for Fourier series.

COROLlaRy 3. Let $\alpha$ satisfy $0 \leqq \alpha<1$, and let $\left\{\varepsilon_{n}\right\} \in b v$ be such that

(i ) $\sum_{n}^{\infty}\left|\Delta \varepsilon_{k}\right|=O\left(\left|\varepsilon_{n}\right|\right)$ and

(ii) $\left\{\frac{1}{n^{\alpha}} \sum_{n}^{\infty} \frac{\left|\varepsilon_{k}\right|}{k^{1-\alpha}}\right\} \in B$.

If $\phi_{\alpha}(t) \in B V(0, \pi)$, then $\sum A_{n}(x) \varepsilon_{n}$ is absolutely convergent.

Results in somewhat weaker form are eventually known in as much as they could be deduced from the theorem of Cheng [5], Prased and Bhatt [14], or the Corollary 2, with an application of a result of Kogbetliantz ([11]).

6.4. The case $\left\{\varepsilon_{n}\right\} \equiv\{1\}$ yields the following:

Corollary 4. Let $0 \leqq \alpha<1$ and let $\left\{p_{n}\right\} \in \mathscr{M l}$ and be such that

$$
\left\{\frac{P_{n}}{n^{\alpha}} \sum_{n}^{\infty} \frac{1}{k^{1-\alpha} P_{k}}\right\} \in B
$$

If $\phi_{\alpha}(t) \in B V(0, \pi)$, then $\sum A_{n}(x) \in\left|N, p_{n}\right|$.

A more general result in this direction is also known and is given elsewhere (Dikshit [7], [9]; see also Lal [12]).

6.5. Writing $\left\{\varepsilon_{n}\right\}=\left\{P_{n} \lambda_{n} / n^{\alpha}\right\}$ we obtain:

Corollary 5. Let $\alpha$ satisfy $0 \leqq \alpha<1$, and let $\left\{p_{n}\right\} \in \mathscr{M}$ and $\left\{\lambda_{n}\right\}$ be a sequence such that

(i) $\left\{\frac{P_{n} \lambda_{n}}{n^{\alpha}}\right\} \in b v$,

(ii) $\sum_{n}^{\infty}\left|\Delta\left(\frac{P_{k} \lambda_{k}}{k^{\alpha}}\right)\right|=O\left(\frac{P_{n}\left|\lambda_{n}\right|}{n^{\alpha}}\right)$ and 
(iii) $\left\{\frac{P_{n}}{n^{\alpha}} \sum_{n}^{\infty} \frac{\left|\lambda_{k}\right|}{k}\right\} \in B$.

If $\phi_{\alpha}(t) \in B V(0, \pi)$, then $\sum A_{n}(x) P_{n} \lambda_{n} / n^{\alpha} \in\left|N, p_{n}\right|$.

It is worthwhile to compare the result of this Corollary for $\alpha=0$ with one due to T. Singh [16] and L. B. Singh [15] and for $0<\alpha<1$, with those due to Nand Kishore [10] and Bhatt [2].

The author would like to thank the referee for the very valuable suggestions.

\section{REFERENCES}

1. S. N. Bhatt, On the absolute summability factors of Fourier series, Annali di Matematica pura ed applicata (4), 72 (1966), 253-266.

2. - A note on the absolute Nörlund summability of a factored Fourier series, Indian J. Math., 11 (1969), 37-42.

3. L. S. Bosanquet, Note on the absolute summability $(C)$ of a Fourier series, J. London Math. Soc., 11 (1936), 11-15.

4. The absolute Cesàro summability of a Fourier series, Proc. London Math. Soc., (2), 41 (1936), 517-528.

5. M. T. Cheng, Summability factors of Fourier series at a given point, Duke Math.

J., 15 (1948), 29-36.

6. G. Das, Tauberian theorems for absolute Nörlund summability, Proc. London Math. Soc., (3), 19 (1969), 357-384.

7. G. D. Dikshit, On the absolute Nörlund summability of a Fourier series, Indian J. Math., 9 (1967), 331-342.

8. ㄴ. A note on Riesz and Nörlund means, Rendiconti del Cirolo Mat. di Palermo (2), 18 (1969), 49-61.

9. - Absolute Nörlund summability of Fourier series, Mathematical Chronicle, 2 (1973), 117-124.

10. Nand Kishore, Absolute Nörlund summability of a factored Fourier series, Indian J. Math., 9 (1967), 123-136.

11. E. Kogbetliantz, Sur les séries absolument sommable par la méthode des moyennes arithmétiques, Bull. des. Sc. Math., (2), 49 (1925), 234-256.

12. S. N. Lal, On the obsolute Nörlund summability of a Fourier series, Indian J. Math., 13 (1971), 51-67.

13. L. McFadden, Absolute Nörlund summability, Duke Math. J., 9 (1942), 168-207.

14. B. N. Prasad and S. N. Bhatt, The summability factors of a Fourier series, Duke Math. J., 24 (1957), 103-117.

15. L. B. Singh, Absolute Nörlund summability of a factored Fourier series, Indian J. Math., 12 (1970), 189-194.

16. T. Singh, Absolute Nörlund smmability of a factored Fourier series, Indian J. Math., 9 (1967), 227-236.

17. O. P. Varshney, On the absolute harmonic summability of a series related to a Fourier series, Proc. American Math. Soc., 10 (1959), 784-789.

18. A. Zygmund, Trigonometric series, Vol. 1, Cambridge University Press, New York, 1959.

Received October 8, 1975 and in revised form January 9, 1976.

University of Auckland, New Zealand 



\title{
PACIFIC JOURNAL OF MATHEMATICS
}

\author{
EDITORS
}

\author{
RICHARD ARENS (Managing Editor) \\ University of California \\ Los Angeles, California 90024
}

\author{
R. A. Beaumont \\ University of Washington \\ Seattle, Washington 98105
}

J. DugundjI

Department of Mathematics

University of Southern California

Los Angeles, California 90007

D. Gilbarg and J. Milgram

Stanford University

Stanford, California 94305

\section{ASSOCIATE EDITORS}
E. F. BECKENBACH
B. H. NEUMANN
F. WOLF
K. Yoshida

\section{SUPPORTING INSTITUTIONS}

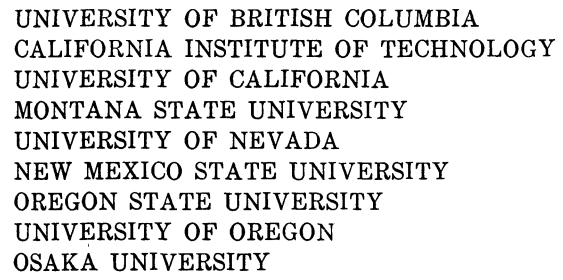

UNIVERSITY OF BRITISH COLUMBIA CALIFORNIA INSTITUTE OF TECHNOLOGY UNIVERSITY OF CALIFORNIA MONTANA STATE UNIVERSITY UNIVERSITY OF NEVADA NEW MEXICO STATE UNIVERSITY OREGON STATE UNIVERSITY UNIVERSITY OF OREGON OSAKA UNIVERSITY

\author{
UNIVERSITY OF SOUTHERN CALIFORNIA \\ STANFORD UNIVERSITY \\ UNIVERSITY OF HAWAII \\ UNIVERSITY OF TOKYO \\ UNIVERSITY OF UTAH \\ WASHINGTON STATE UNIVERSITY \\ UNIVERSITY OF WASHINGTON

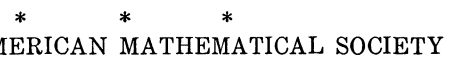

The Supporting Institutions listed above contribute to the cost of publication of this Journal, but they are not owners or publishers and have no responsibility for its content or policies.

Mathematical papers intended for publication in the Pacific Journal of Mathematics should be in typed form or offset-reproduced, (not dittoed), double spaced with large margins. Please do not use built up fractions in the text of your manuscript. You may however, use them in the displayed equations. Underline Greek letters in red, German in green, and script in blue. The first paragraph or two must be capable of being used separately as a synopsis of the entire paper. Items of the bibliography should not be cited there unless absolutely necessary, in which case they must be identified by author and Journal, rather than by item number. Manuscripts, in triplicate, may be sent to any one of the editors. Please classify according to the scheme of Math. Reviews, Index to Vol. 39. All other communications should be addressed to the managing editor, or Elaine Barth, University of California, Los Angeles, California, 90024.

The Pacific Journal of Mathematics expects the author's institution to pay page charges, and reserves the right to delay publication for nonpayment of charges in case of financial emergency.

100 reprints are provided free for each article, only if page charges have been substantially paid. Additional copies may be obtained at cost in multiples of 50 .

The Pacific Journal of Mathematics is issued monthly as of January 1966. Regular subscription rate: $\$ 72.00$ a year (6 Vols., 12 issues). Special rate: $\$ 36.00$ a year to individual members of supporting institutions.

Subscriptions, orders for back numbers, and changes of address should be sent to Pacific Journal of Mathematics, 103 Highland Boulevard, Berkeley, California, 94708.

PUBLISHED BY PACIFIC JOURNAL OF MATHEMATICS, A NON-PROFIT CORPORATION

Printed at Kokusai Bunken Insatsusha (International Academic Printing Co., Ltd.), 8-8, 3-chome, Takadanobaba, Shinjuku-ku, Tokyo 160, Japan.

Copyright (C) 1975 by Pacific Journal of Mathematics Manufactured and first issued in Japan 


\section{Pacific Journal of Mathematics}

\section{Vol. 63, No. 2 \\ April, 1976}

Joseph Anthony Ball and Arthur R. Lubin, On a class of contractive perturbations

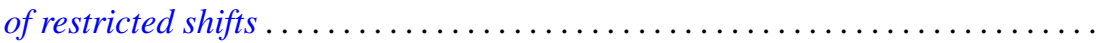

Joseph Becker and William C. Brown, On extending higher derivations generated

by cup products to the integral closure .......................

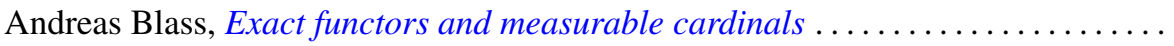

Joseph Eugene Collison, A variance property for arithmetic functions . . . . . . . . . .

Craig McCormack Cordes, Quadratic forms over nonformally real fields with a

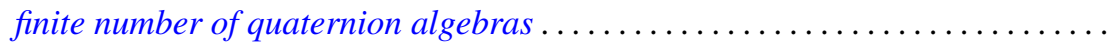

Freddy Delbaen, Weakly compact sets in $H^{1} \ldots \ldots \ldots \ldots \ldots \ldots \ldots \ldots \ldots$

G. D. Dikshit, Absolute Nörlund summability factors for Fourier series ..........

Edward Richard Fadell, Nielsen numbers as a homotopy type invariant. . ........

Josip Globevnik, Analytic extensions of vector-valued functions . . . . . . . . . . . .

Robert Gold, Genera in normal extensions . . . . . . . . . . . . . . . . . . . 389

Solomon Wolf Golomb, Formulas for the next prime

Robert L. Griess, Jr., The splitting of extensions of $S L(3,3)$ by the vector space

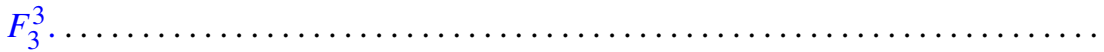

Thomas Alan Keagy, Matrix transformations and absolute summability .........

Kazuo Kishi, Analytic maps of the open unit disk onto a Gleason part.

Kwangil Koh, Jiang Luh and Mohan S. Putcha, On the associativity and commutativity of algebras over commutative rings . ..... . .

James C. Lillo, Asymptotic behavior of solutions of retarded differential difference equations.

John Alan MacBain, Local and global bifurcation from normal eigenvalues ..

Anna Maria Mantero, Sets of uniqueness and multiplicity for $L^{p}$

J. F. McClendon, Embedding metric families

L. Robbiano and Giuseppe Valla, Primary powers of a prime ideal .

Wolfgang Ruess, Generalized inductive limit topologies and barrelledness

properties.

Judith D. Sally, Bounds for numbers of generators of Cohen-Macaulay ideals

Helga Schirmer, Mappings of polyhedra with prescribed fixed points and fixed point indices.

Cho Wei Sit, Quotients of complete multipartite graphs

S. Sznajder and Zbigniew Zielezny, Solvability of convolution equations in $\mathscr{K}_{p}^{\prime}$,

$p>1$.

Mitchell Herbert Taibleson, The existence of natural field structures for finite

dimensional vector spaces over local fields

William Yslas Vélez, A characterization of completely regular fields

P. S. Venkatesan, On right unipotent semigroups ..............

Kenneth S. Williams, A rational octic reciprocity law ............

Robert Ross Wilson, Lattice orderings on the real field .......... 